\title{
Respiratory morbidity after repair of oesophageal atresia and tracheo-oesophageal fistula
}

\author{
P Chetcuti, P D Phelan
}

\begin{abstract}
Respiratory morbidity in 334 patients aged 1 to 37 years with repaired oesophageal atresia and tracheo-oesophageal fistula is reported. Just under half the patients were subsequently hospitalised with respiratory illness. Two thirds of admissions were before 5 years of age. Five percent were admitted on more than five occasions. Patients with gastrooesophageal reflux and low birth weight were more likely to be admitted. Thirty one percent of patients had one or more episodes of pneumonia in the first five years of life and 5\% after 15 years. The prevalence of annual bouts of bronchitis in these age groups was $74 \%$ and $41 \%$ respectively. The prevalence of wheeze was about $40 \%$ in all age groups. Patients with symptoms persisting after 15 years were more likely to have had lower respiratory tract illness in early childhood and a history of atopy. In the 12 months before review, weekly episodes of wheezing were present in one third under 5 years and $15 \%$ over 15 years. Thirty two percent of patients aged 5-10 years and $8 \%$ over 15 years missed two or more weeks of school or work in the previous year with respiratory illness.
\end{abstract}

(Arch Dis Child 1993;68:167-70)

Oesophageal atresia and tracheo-oesophageal fistula are uncommon congenital anomalies occurring in one in 4500 live births. ${ }^{1}$ Improved survival over the last 20 years ${ }^{2} 3$ has resulted in an increased awareness of their long term complications. Respiratory morbidity after initial surgery was first reported in 1966 with a description of aspiration pneumonia in 14 patients. ${ }^{4}$ Subsequently, recurrent lower respiratory tract infections, ${ }^{56}$ and minor lung function abnormalities, ${ }^{7-10}$ have been reported in small numbers of patients. Multiple factors may contribute to these problems including recurrent inhalation of gastric or oesophageal contents, ${ }^{11}$ structural instability of the major airways, ${ }^{12} 13$ and abnormal airway epithelium. ${ }^{14}$

Knowledge of the prevalence of respiratory disease in a large group of patients after repair of oesophageal atresia and tracheo-oesophageal fistula would be of considerable value to paediatricians and paediatric surgeons and would improve their ability to counsel parents about the likelihood of future problems. This study reports the respiratory morbidity of a large number of children and adults, who represent over $90 \%$ of all the survivors born with oesophageal atresia from a major centre. Gastro- intestinal symptoms and growth and lung function abnormalities in these patients will be reported elsewhere.

\section{Patients and methods}

Five hundred and thirty eight patients with oesophageal atresia and tracheo-oesophageal fistula were managed at the Royal Children's Hospital, Melbourne, from the first successful repair in 1948 until 1986. Three hundred and sixty six patients survived of whom 302 were interviewed and examined as part of a follow up study, and information was available from a telephone interview for a further 32 patients. The majority of adult patients were accompanied by their parents.

The following information was recorded from the case notes: birth weight, gestation, type of oesophageal atresia, complications relating to the upper gastrointestinal tract, episodes of radiological pneumonia, and admissions with respiratory illness. Patients undergoing two or more oesophageal dilatations were classed as having a significant oesophageal stricture, and gastro-oesophageal reflux was defined on radiological and/or endoscopic criteria.

Details of medical history and health problems in the previous 12 months with emphasis on gastrointestinal and respiratory symptoms and illnesses were obtained from the patients and where possible the parents. Bronchitis was defined as an episode of worsening cough, rattling, and constitutional upset lasting for five days or more; a persistent cough as a daily troublesome cough lasting for one year and wheeze as a 'whistling noise' from the chest. The presence of the typical harsh, brassy cough was also recorded and regarded as evidence of tracheomalacia. A history of atopic disease (asthma, hay fever, eczema, urticaria) in the patient and first degree relatives and cigarette smoking was documented.

The $\chi^{2}$ test was used to determine the relationship between possible risk factors in patients hospitalised with respiratory illness compared with non-hospitalised patients, and between possible risk factors in older patients with persisting respiratory symptoms compared with their asymptomatic peers.

\section{Results}

Data on respiratory symptoms and illnesses in 334 patients aged 1-37 years are reported. The age and sex distribution is shown in table 1. Two hundred and ninety patients $(87 \%)$ had oesophageal atresia and distal tracheo-oesopha- 
Table 1 Age and sex distribution

\begin{tabular}{lllll}
\hline \multicolumn{5}{c}{ Age (years) } \\
\cline { 2 - 5 } & $0-5$ & $5-10$ & $10-15$ & $>15$ \\
\hline Male & 39 & 30 & 31 & 92 \\
Female & 23 & 24 & 23 & 72 \\
\hline
\end{tabular}

Table 2 Age of patients at admission

\begin{tabular}{lc}
\hline Age (years) & No $(\%)$ of admissions \\
\hline$<5$ & $337(73)$ \\
$5-10$ & $92(20)$ \\
$10-15$ & $31(7)$ \\
$>15$ & $1(<1)$ \\
\hline
\end{tabular}

Table 3 Number of admissions in 147 patients

\begin{tabular}{ll}
\hline No of admissions & No $(\%)$ of patients \\
\hline 1 & $62(42)$ \\
2 & $25(17)$ \\
$3-5$ & $44(30)$ \\
$6-10$ & $11(8)$ \\
$>10$ & $5(3)$ \\
\hline
\end{tabular}

Table 4 Characteristics of hospitalised patients compared with non-hospitalised patients

\begin{tabular}{|c|c|c|c|}
\hline & $\begin{array}{l}\% \\
\text { Hospitalised }\end{array}$ & $\begin{array}{l}\% \text { Not } \\
\text { hospitalised }\end{array}$ & p Value \\
\hline \multicolumn{4}{|l|}{ Sex: } \\
\hline Males & 48 & 52 & \multirow[t]{2}{*}{$0 \cdot 14$} \\
\hline Females & 39 & 61 & \\
\hline \multicolumn{4}{|l|}{ Gestation (weeks): } \\
\hline$<37$ & 52 & 48 & \multirow[t]{2}{*}{$0 \cdot 17$} \\
\hline$>37$ & 42 & 58 & \\
\hline \multicolumn{4}{|l|}{ Birth weight $(\mathrm{g})$} \\
\hline$<2500$ & 54 & 46 & \multirow[t]{2}{*}{$<0.02$} \\
\hline$>2500$ & 40 & 60 & \\
\hline \multicolumn{4}{|l|}{ Allergy history } \\
\hline Yes & 45 & 55 & \multirow[t]{2}{*}{$0 \cdot 2$} \\
\hline No & 38 & 62 & \\
\hline \multicolumn{4}{|l|}{ Parental smoking } \\
\hline Yes & 46 & 54 & \multirow[t]{2}{*}{$0 \cdot 28$} \\
\hline No & 40 & 60 & \\
\hline With radiological gastro-oesophageal reflux & 62 & 38 & \multirow[t]{2}{*}{$<0.0001$} \\
\hline No gastro-oesophageal reflux & 29 & 71 & \\
\hline \multicolumn{4}{|l|}{ Oesophageal stricture } \\
\hline Yes & 51 & 49 & \multirow[t]{2}{*}{$0 \cdot 14$} \\
\hline No & 42 & 58 & \\
\hline
\end{tabular}

Table 5 Prevalence (\%) of respiratory problems in different age groups in all patients

\begin{tabular}{|c|c|c|c|c|}
\hline & \multicolumn{4}{|c|}{ Age (years) } \\
\hline & $0-5$ & $5-10$ & $10-15$ & $>15$ \\
\hline $\begin{array}{l}\text { Persistent cough } \\
\text { Typical harsh cough } \\
\text { Recurrent wheeze } \\
\text { Annual bouts of bronchitis } \\
\text { Radiological pneumonia }\end{array}$ & $\begin{array}{r}87(27) \\
234(75) \\
147(40) \\
216(74) \\
101(31)\end{array}$ & $\begin{array}{r}35(14) \\
152(59) \\
94(37) \\
160(62) \\
27(11)\end{array}$ & $\begin{array}{r}21(10) \\
101(47) \\
75(37) \\
95(46) \\
7(3)\end{array}$ & $\begin{array}{r}12(8) \\
63(42) \\
59(40) \\
60(41) \\
7(5)\end{array}$ \\
\hline
\end{tabular}

Table 6 Characteristics of patients over 15 years with respiratory symptoms compared with asymptomatic patients of the same age

\begin{tabular}{|c|c|c|c|}
\hline & Symptomatic & Asymptomatic & p Value \\
\hline \multicolumn{4}{|l|}{ Sex } \\
\hline Male & 53 & 47 & \multirow[t]{2}{*}{$0 \cdot 25$} \\
\hline Female & 63 & 37 & \\
\hline \multicolumn{4}{|c|}{ Allergy history } \\
\hline Yes & 63 & 37 & \multirow[t]{2}{*}{$0 \cdot 02$} \\
\hline No & 43 & 57 & \\
\hline \multicolumn{4}{|c|}{ Cigarette smokers } \\
\hline Yes & 65 & 35 & \multirow[t]{2}{*}{$0 \cdot 17$} \\
\hline No & 52 & 48 & \\
\hline \multicolumn{4}{|c|}{$\begin{array}{l}\text { Lower respiratory tract illness } \\
\text { in early childhood }\end{array}$} \\
\hline Yes & 68 & 32 & \multirow[t]{2}{*}{0.0001} \\
\hline No & 24 & 76 & \\
\hline \multicolumn{4}{|c|}{$\begin{array}{l}\text { Persisting gastro-oesophageal } \\
\text { reflux symptoms }\end{array}$} \\
\hline Yes & 55 & 45 & \multirow[t]{2}{*}{$0 \cdot 63$} \\
\hline No & 59 & 41 & \\
\hline
\end{tabular}

geal fistula. Atresia and proximal fistula was present in six (2\%), atresia alone in $16(5 \%)$, and a fistula with an intact oesophagus in $22(6 \%)$.

One hundred and forty seven patients $(44 \%)$ were hospitalised with respiratory illnesses in the years after initial surgery. There were a total of 461 hospital admissions. The age of the patients at admission and the number of admissions are shown in tables 2 and 3. Forty eight percent of patients aged 5-15 years were admitted in the first five years of life compared with $45 \%$ over 15 years of age. The number of admissions was similar in the two groups. The characteristics of the hospitalised patients compared with non-hospitalised patients and $p$ values are shown in table 4. Low birthweight patients and patients with gastro-oesophageal reflux were more likely to be admitted.

The prevalence of cough, recurrent wheeze, annual bouts of bronchitis, and radiological pneumonia in different age groups for all ages is shown in table 5. Details of respiratory symptoms and illnesses in the first five years of life were not recalled by 34 patients and/or their parents. Fifty one $(50 \%)$ of the 101 patients with pneumonia in the $0-5$ year age group had more than one episode and $26(25 \%)$ had three or more episodes. Ten (37\%) of the 27 patients with pneumonia in the 5-10 year age group had more than one episode. Eighty four patients, 15 years and older $(57 \%)$, had persisting respiratory symptoms. The characteristics of these patients compared with the asymptomatic patients in the same age groups and $p$ values are shown in table 6. Patients with early childhood respiratory illness and those with a history of atopy were more likely to have symptoms.

Prevalence of wheeze and bronchitis in the 12 months before review in the different age groups is shown in figs 1 and 2 . In the 12 months before review a persistent cough was present in $32 \%$ aged $0-5$ years, $13 \% 5-10$ years, $15 \% 10-15$ years, and $9 \%$ over 15 years. The typical harsh cough was present during a coughing bout in $71 \%$ aged $0-5$ years, $60 \%$ aged $5-10$ years, $57 \%$ aged $10-15$ years and $40 \%$ over 15 years. Episodes of airway obstruction unrelated to feeding and resulting in cyanosis were
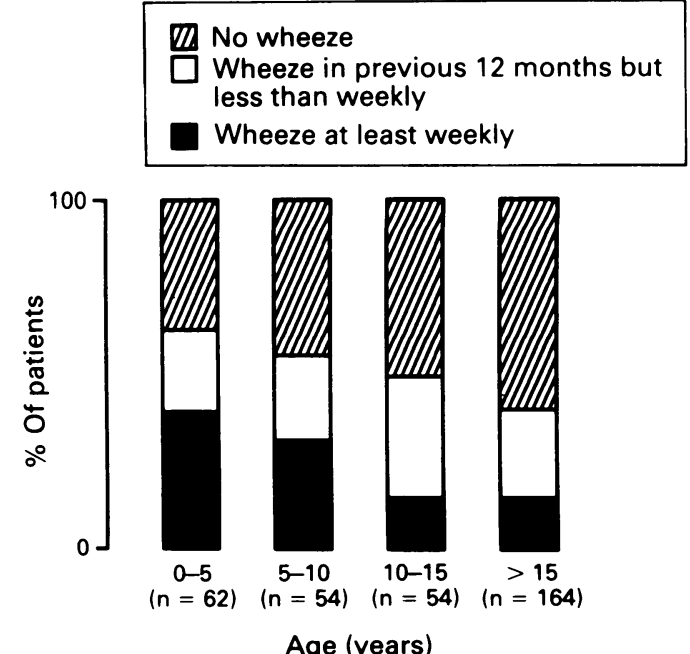

Figure 1 Current age of patient and prevalence of wheeze in the 12 months to review. 

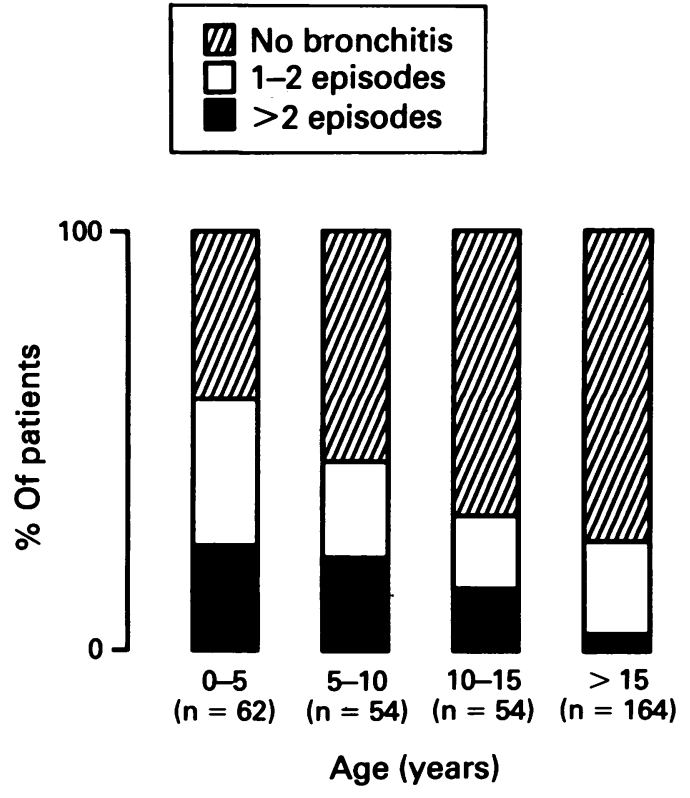

Figure 2 Current age of patient and prevalence of bronchitis in the 12 months to review.

Table 7 The percent of days missed from school/work in the different age groups

\begin{tabular}{lllr}
\hline \begin{tabular}{l} 
No of $\begin{array}{l}\text { Noys off } \\
\text { dace }\end{array}$ \\
\cline { 2 - 4 }
\end{tabular} & $5-10$ & $10-15$ & $>15$ \\
\hline 0 & 31 & 32 & 61 \\
$<5$ & 22 & 43 & 25 \\
$5-10$ & 15 & 11 & 6 \\
$10-20$ & 17 & 7 & 5 \\
$>20$ & 15 & 7 & 3 \\
\hline
\end{tabular}

described in $8 \%$ aged $0-5$ years but were not present in older patients. The number of days missed from school or work in the different age groups in the previous 12 months is shown in table 7. Six adult patients were unemployed and eight were housewives. Only five patients aged 5 and over admitted to not participating in sport because of chronic respiratory symptoms.

\section{Discussion}

This study of a large number of survivors after surgical repair of oesophageal atresia and fistula shows that respiratory complications in the years after initial surgery are very common. Just under half the group were hospitalised with respiratory illness, most commonly in early childhood and one third of younger school aged children missed two or more weeks of school a year with respiratory disease. Episodes of pneumonia and annual bouts of bronchitis were present in one third and two thirds of the patients under 5 years of age respectively and declined in frequency in the older age groups. The prevalence of wheeze showed a much slower decline, present in $63 \%$ under 5 years of age and $40 \%$ over 15 years of age. These findings contrast dramatically with the expected prevalence of respiratory illness in a normal population with a hospitalisation rate of $5 \%$ in the first four years, ${ }^{15} 16$ one episode of bronchitis in $25 \%$ of children before 7 years, ${ }^{17}{ }^{18}$ pneumonia in $3 \%$ of 3 year olds, ${ }^{19}$ and a point preva- lence of wheeze of 10 to $24 \%$ for $7-15$ year olds. ${ }^{20} 21$

The findings of this study are of considerable importance to paediatricians and paediatric surgeons both in counselling parents of babies born with oesophageal atresia and in reviewing older patients, optimising their management and considering the predisposing factors.

The reliability of some of our data may be questioned. Details of radiological pneumonia and admissions were obtained from the hospital records only, and as the majority of patients were treated subsequently in our hospital these data are accurate. Parental recollection of early childhood respiratory illness may not be reliable, ${ }^{22}{ }^{23}$ but this has not been studied in parents of children known to have had troublesome symptoms. The only study on prevalence of respiratory disease in relation to oesophageal atresia was on 100 selected patients up to 20 years of age from this same group reviewed 12 years previously. ${ }^{6}$ It reported that two thirds had more than four bouts of bronchitis a year under 3 years of age and half over 8 years of age. In view of our concerns about the reliability of parental recollection, we have only reported the number of patients experiencing at least one episode of bronchitis per year. Similarly, we have not commented on wheeze frequency in these data.

Although a similar number of adults and children were admitted with respiratory illness in early childhood, these groups may not be comparable. With the advent of neonatal intensive care and mechanical ventilation in the early 1970 s, patients who formerly would have died are now surviving and are likely to have more severe lung disease. Low birthweight babies in our study were more likely to need readmission. Only minor changes in the surgery have taken place since 1950 and this is much less likely to influence respiratory morbidity. In the late 1970s a posterolateral thoracotomy through an intercostal approach superseded a rib bed approach and the routine use of gastrostomy for all repairs was abandoned.

Patients with gastro-oesophageal reflux were more likely to be hospitalised with respiratory illness. This is common after repaired oesophageal atresia. ${ }^{5}$ Mobilisation of the lower oesophageal segment may produce traction on the lower oesophagus with distortion of the gastrooesophageal junction and interference with the neurovascular supply of the lower oesophagus. ${ }^{24}$ There may be an inherent abnormality in the nerve supply of the upper gastrointestinal tract. $^{25}$ Furthermore gastrostomy when performed may produce reflux. ${ }^{3}$ Gastrooesophageal reflux may result in the inhalation of gastric contents with increased bronchial hyperreactivity, recurrent lower airways infections, and possibly permanent bronchiolar and parenchymal damage. Reflux may also initiate vagally mediated bronchoconstriction in the absence of inhalation. ${ }^{2627}$

Other factors may contribute to respiratory disease in oesophageal atresia. Disordered oesophageal peristalsis is universal after repair ${ }^{5} 28$ and may lead to inhalation. Tracheomalacia resulting in variable narrowing of the 
trachea was probably responsible for the worrying episodes of cyanosis described in the younger patients in our series. It may also facilitate the development of expiratory wheezing with intercurrent lower respiratory infection and produce the typical 'tof' cough that was present in two thirds of our patients under 5 years of age and one third over 15 years. This is a relatively ineffective cough and together with squamous metaplasia of the tracheal mucosa ${ }^{14}$ and loss of cilial activity may lead to secretion retention and secondary infection.

Just over half the patients over 15 years had persisting respiratory symptoms. Fortunately only $15 \%$ had frequent wheeze and fewer than $10 \%$ frequent annual episodes of bronchitis. The majority were employed, missed little time off work with illness, and participated fully in sports. Patients with allergic symptoms and a family history of allergy, and patients who experienced early childhood respiratory illness, were more likely to have persisting symptoms. These findings suggest some of these patients may have had asthma, and would be expected in such a large population. A large group however had persisting respiratory symptoms possibly from lung damage sustained in early childhood. The lack of relationship between gastrooesophageal reflux symptoms and respiratory symptoms in this group would support this, unless inhalation is occurring at a subclinical level. Although we were surprised by the number of smokers in this age group, there was no significant relationship between smoking and respiratory symptoms.

We have shown that patients born with oesophageal atresia experience major respiratory morbidity, particularly in early childhood. Lung function measurements in infants may allow early identification of patients at risk of developing chronic lung disease, ${ }^{29}$ but these tests are difficult, time consuming, and available only in a few centres. We would advocate frequent clinical assessments of these patients, the use of regular chest physiotherapy if symptoms develop and the early identification and treatment of respiratory pathogens. Whether simple antireflux treatments instituted in all infants after initial surgery would be beneficial is not known. In patients with more severe respiratory disease detailed assessments of oesophageal, gastro-oesophageal, and tracheal function are required. If significant upper gastro-intestinal problems are found, the newer prokinetic drugs such as cisapride may be beneficial. ${ }^{30}$ Unfortunately antireflux surgery may result in increasing oesophageal dysmobility. ${ }^{31}$ For life threatening episodes of airway obstruction from severe tracheomalacia, aortopexies have been shown to be helpful. ${ }^{13} 32{ }^{33}$ Many older children and adults in our study have persistent but usually mild respiratory symptoms. Whether they are at risk of chronic lung disease in later life remains to be determined.

1 Myers NA. Oesophageal atresia: the epitome of modern surgery. Ann R Coll Surg Engl 1974:54:277-87.
2 Myers NA. Oesophageal atresia and/or tracheo-oesophageal fistula. A study of mortality. In: Rickman PP, Hecker WC, Prevot S, eds. Causes of postoperative death in children. Baltimore and Munich: Urban and Schwar\%enberg 1979; 141-65.

3 Spitz L, Kiely E, Brereton RJ. Esophageal atresia: five vear experience with 148 cases. $\mathcal{F}$ Pediatr Surg 1987;22:103-8.

+ Chrispin AR. Friedland GW. Waterston DJW. Aspiration pneumonia and dysphagia after technically successful repair of oesophageal atresia. Thorax 1966;81:104-10.

5 Laks H, Wilkinson R, Schuster S. Long term results following correction of esophageal atresia and tracheo-esophageal fistula. F Pediatr Surg 1972;7:591-6.

6 Dudley N, Phelan P. Respiratory complications in long-term survivors of oesophageal atresia. Arch Dis Child 1976;51: 279-82.

7 Milligan D, Levison $\mathrm{H}$. Lung function in children following repair of tracheo-oesophageal fistula. F Pediatr 1979:95: 247

8 Couriel JM, Hibbert M. Olinsky A. Phelan P. Long term pulmonary consequences of (eesophageal atresia with tracheo-oesophageal fistula. Acta Paediatr Siand 1982:71: 973-8

9 Le Soeuf PN, Myers N, Landau L. Etiological factors in long term respiratory function abnormalities following esophageal atresia repair. F Pediatr Surg 1987;22:918-22.

10 Biller JA, Allen JL, Schuster SR, Treves ST, Winter H. Long term evaluation of esophageal and pulmonars function in patients with repaired esophageal atresia and function in patients with repaired esophageal atresia
tracheo-esophageal fistula. Dig Dis $S$ i 1987:32:985-90

11 Shermata DW, Whitington PF. Seto DS, Haller JA. Lower esophageal sphincter dysfunction in esophageal atresia: nocturnal regurgitation and aspiration pneumonia. 7 Pediatr Surg 1977:12:871-6.

12 Wailoo MP, Emery JL. The trachea in children with tracheooesophageal fistula. Histopathology 1979:3:329-38

13 Benjamin B. Cohen D, Glasson M. Tracheomalacia in association with congenital tracheo-esophageal fistula Surgerv 1976:79:504-8

14 Emery JL, Haddadin AJ. Syuamous epithelium in the respiratory tract of children with tracheo-oesophageal respiratory tract of children with

15 Medical Research Council Sub-Committee on Respiratury Syncytial infection. Admissions to hospital in industrial. urban and rural areas. BMF 1978;ii:796-8.

16 Belshe RB. Van Voris LP. Mutson MA. Impact of viral respiratorv diseases on infants and voung children in a rural and urban area of southern west Virginia. $1 \mathrm{~m} \cdot 7$ Epidemol 1983:117:467-74

17 Hall GJC. Gandevia B, Silverstone $H$. The inter-relationship of upper and lower respiratory tract symptoms and signs in seven year old children. Int f Epidemiol 1972:1:389_t03

Is Peat JK, Woolcock AJ. Leeder SR, Blackburn (RB. Asthm and bronchitis in Sidnev school children: I. Prevalence during a six year study. Am f Epidemol 1980:111:721-7,

19 Glezen WP. Denny GW. Epidemiology of acute lower respiratory disease in children. 1 kingl 7 .11:d 1973:288: 498-505.

20 Lee DA. Winslow WR. Speight ANP, Hex FN. Prevalence and spectrum of asthma in childhood. B.117 1982:286: $1256-8$.

21 MeNicol KN. Williams HE. Spectrum at athma in children-1. Clinical and phrsiological component Bitly 1973;iv:7-11.

22 Watkin CJ. Burton P. Leeder S, Sittampalams Y. Werer AM Wiggins R. Doctor diagnosis and maternal recall of lower Wiggins R. Doctor diagnosis and maternal recal
respiratory illness. Int f Epidemiol 1982:11:62--6.

23 Lann JE, Knowelden J. Row JW. Patterns of revertatury illness in Sheffield junior scheril hildren. A follow ur study. British foumal of Precientice and Sicial .Hedhin $1970 ; 24: 223-8$

24 Holder TM, Ashoroft KW. Developments in the are patients with esophageal atresia and tracheo-esophageal fistula. Surg Clin North Am 1981;61:1051-61.

25 Nakazato Y, Landing BH, Wells TR Abnormal Auerbach plexus in the esophagus and stomach of patients with esophageal atresia and tracheo-esophageal fistula. 7 Pedictr esophageal atresia and

26 Damis O, Lasov C, Lauvaom A, Pope CE. Esophageal reflux an unrecognised cause of recurrent obstructive bronchitis in children. 7 Pediatr 1976;89:220-4.

27 Mansfield LE, Stein MR. Gastro-esophageal retlux and asthma: a possible reflux mechanism. Ann Allergv 1978:41 $224-6$

28 Dudley NE. Oesophageal motility and quality of survival in repaired oesophageal atresia. Proceedings of the international symposium on oesophageal atresia. Bremen, 1974.

29 Le Soeuf PN, England SJ, Bryan AC. Passive respiratory mechanics in newborns and children. Am Rev Respir Dis 1984;129:552-6.

30 Cucchiara S, Staiano A, Boisieri A, et al. Effects of cisapride on parameters of oesophageal motility and on the prolonged on parameters of oesophageal motility and on the prolonged
intra-oesophageal pH test in infants with gastro-oesophageal intra-oesophageal pH test in infan
reflux disease. Gut 1990;31:21-5.

31 Carci MR. Dibbins AW. Problems associated with a Nissen fundoplication following tracheo-esophageal fistula and esophageal atresia repair. Arch Surg 1988;123:618-20.

32 Blair G, Cohen R, Tiller RM. Treatment of tracheomalacia eight years' experience. F Pediatr Surg 1986;21:781-5.

33 Kiely EM, Spitz L, Brereton R. Management of tracheo malacia by aortopexy. Pediatric Surgery International 1987 2:13-5. 